\title{
Postoperative subconjunctival bevacizumab injection as an adjunct to 5 -fluorouracil in the management of scarring after trabeculectomy
}

This article was published in the following Dove Press journal:

Clinical Ophthalmology

19 June 2013

Number of times this article has been viewed

Florentina Joyce Freiberg' Juliane Matlach'

Franz Grehn'

Sabine Karl ${ }^{2}$

Thomas Klink'

'Department of Ophthalmology, Julius Maximilian University, Wuerzburg, Germany; ${ }^{2}$ Institute of Mathematics, University of Wuerzburg, Wuerzburg, Germany

Correspondence: Florentina Joyce Freiberg

Department of Ophthalmology, Julius Maximilian University, Joseph-SchneiderStrasse II, 97080 Wuerzburg, Germany Tel +4920120602

Fax +4920I 20490

Email f.freiberg@augenklinik.

uni-wuerzburg.de
Purpose: Scarring after glaucoma filtering surgery remains the most frequent cause for bleb failure. The aim of this study was to assess if the postoperative injection of bevacizumab reduces the number of postoperative subconjunctival 5-fluorouracil (5-FU) injections. Further, the effect of bevacizumab as an adjunct to 5-FU on the intraocular pressure (IOP) outcome, bleb morphology, postoperative medications, and complications was evaluated.

Methods: Glaucoma patients $(\mathrm{N}=61)$ who underwent trabeculectomy with mitomycin $\mathrm{C}$ were analyzed retrospectively (follow-up period of $25 \pm 19$ months). Surgery was performed exclusively by one experienced glaucoma specialist using a standardized technique. Patients in group 1 received subconjunctival applications of 5-FU postoperatively. Patients in group 2 received 5-FU and subconjunctival injection of bevacizumab.

Results: Group 1 had $6.4 \pm 3.3(0-15)$ (mean \pm standard deviation and range, respectively) 5-FU injections. Group 2 had $4.0 \pm 2.8$ (0-12) (mean \pm standard deviation and range, respectively) 5 -FU injections. The added injection of bevacizumab significantly reduced the mean number of 5-FU injections by $2.4 \pm 3.08$ ( $P \leq 0.005$ ). There was no significantly lower IOP in group 2 when compared to group 1 . A significant reduction in vascularization and in cork screw vessels could be found in both groups ( $P<0.0001,7$ days to last 5-FU), yet there was no difference between the two groups at the last follow-up. Postoperative complications were significantly higher for both groups when more 5-FU injections were applied. $(P=0.008)$. No significant difference in best corrected visual acuity $(P=0.852)$ and visual field testing $(P=0.610)$ between preoperative to last follow-up could be found between the two groups.

Conclusion: The postoperative injection of bevacizumab reduced the number of subconjunctival 5-FU injections significantly by 2.4 injections. A significant difference in postoperative IOP reduction, bleb morphology, and postoperative medication was not detected.

Keywords: bevacizumab, 5-fluorouracil, glaucoma, trabeculectomy, bleb failure, bleb scarring

\section{Introduction}

Glaucoma is a heterogeneous group of ocular disorders leading to optic neuropathy and, if left untreated, leading to visual field loss. To prevent the progression of glaucoma, lowering the intraocular pressure (IOP) is inevitable. ${ }^{1}$ In many cases, IOP lowering cannot be achieved without glaucoma filtering surgery. In 1968, Cairns introduced the trabeculectomy (TET), which is still the gold standard in glaucoma surgery. ${ }^{2}$ Nevertheless, conjunctival scarring remains the most frequent cause for bleb failure after TET. The transdifferentiation of fibroblasts into myofibroblasts is mainly responsible for scar formation leading to bleb failure and a rise in IOP. ${ }^{3}$ Intra- and postoperatively applied antimetabolites, such as 5-fluorouracil (5-FU) and mitomycin C (MMC) 
have been shown to reduce postoperative scar formation. ${ }^{4}$ Due to their nonspecific effect on cell biology, the application can lead to cell damage followed by bleb leakage, hypotony, corneal scarring, and endophthalmitis. ${ }^{5,6}$ Thus, their application is limited and alternatives are needed.

Vascular endothelial growth factor (VEGF) is a cytokine with multiple effects on wound healing. ${ }^{7,8}$ Through collagen deposition, angiogenesis, and epithelialization scar formation is stimulated. ${ }^{7}$ VEGF has been shown to be elevated in glaucoma patients and to enhance scar formation. ${ }^{9-11}$ Bevacizumab (Avastin; Genentech, San Francisco, CA, USA) is a full length humanized monoclonal antibody that binds to all isoforms of VEGF. It has been approved by the US Food and Drug Administration for intravenous treatment of metastatic colorectal cancer. ${ }^{12}$ Current case reports have shown evidence of reduced bleb failure after subconjunctival injections of bevacizumab. ${ }^{13-15}$ Further studies in the rabbit and in vitro studies have shown a reduction in postoperative scarring and bleb failure using bevacizumab alone or as an adjunct to 5-FU. ${ }^{16,17,21-23}$

The aim of this study was to assess if a single postoperative injection of bevacizumab reduces the number of postoperative subconjunctival 5-FU injections in glaucoma patients. Further, we evaluated the effect of bevacizumab as an adjunct to 5-FU on the IOP outcome, bleb morphology, postoperative medication, and complications.

\section{Patients and methods}

Glaucoma patients $(\mathrm{N}=61)$ who underwent TET with MMC were analyzed in a nonrandomized, retrospective, comparative study with a mean follow-up period of $25 \pm 19$ months. Inclusion criteria were patients over 18 years with primary open angle glaucoma, pseudoexfoliation glaucoma, normal tension glaucoma, pigment dispersion glaucoma, ocular hypertension, and primary angle closure glaucoma. Surgery was performed exclusively by one experienced glaucoma specialist (F. Grehn) using a standardized technique at the University Eye Hospital, Wuerzburg, Germany. All surgeries were performed under general anesthesia. Postoperative examinations were performed at the clinic of the surgeon who performed the TET. Postoperatively, one group of patients received subconjunctival applications of 5-FU exclusively (group 1). The other group of patients received subconjunctival 5-FU and a single injection of subconjunctival bevacizumab (group 2). Each injection of $0.5 \mathrm{~mL} 5$-FU contained $5.0 \mathrm{mg} 5$-FU in $0.9 \%$ sodium chloride solution (Cytostatica Pharmacy, University Hospital Wuerzburg, Wuerzburg, Germany). Each injection of $0.14 \mathrm{~mL}$ bevacizumab contained
$3.5 \mathrm{mg}$ of bevacizumab (Avastin; Genentech, San Francisco, CA, USA). Patients received detailed explanations and counseling, and informed consent was given for all procedures. Patients were divided into the two subgroups according to time: before 2008, patients received subconjunctival 5-FU and after 2008, patients received adjunctive bevacizumab injections as a standard procedure. Best corrected visual acuity (BCVA), IOP, number of antiglaucomatous medications, and visual field examination were analyzed pre- and postoperatively, at days 1 and 7 after 1, 3, 6, and 12 months, and at the last follow-up. The Wuerzburg bleb classification score (WBCS) was used for standardized filtering bleb analysis at the same time as the other examinations. ${ }^{18}$ It is a grading system for clinical bleb morphology, and evaluates vascularization, corkscrew vessels, encapsulation, and microcysts. ${ }^{18,19}$ IOP was measured by Goldmann applanation tonometry after topical fluorosceine oxybuprocaine (SDU Faure, OmniVision AG, Neuhausen, Switzerland). Visual field screening was performed with the Octopus ${ }^{\circledR} 101$ and 900 perimeter (Haag-Streit UK, Essex, UK). Complete success was defined as (1) an IOP $\leq 21 \mathrm{mmHg}$ and $>20 \%$ pressure reduction from baseline without glaucoma medication or (2) IOP $\leq 18 \mathrm{mmHg}$ without glaucoma medication. Qualified success was defined as (1) an IOP $\leq 21 \mathrm{mmHg}$ and $>20 \%$ pressure reduction from baseline with or without glaucoma medication or (2) IOP $\leq 18 \mathrm{mmHg}$ with and without glaucoma medication.

Multiple comparison $t$-tests were performed to test for significance between treatment pairs. Poisson regression was performed to model count data for postoperative complications. The Wilcoxon test was used to compare the changes in WBCS over time. The level of significance applied to the statistical analysis was $P \leq 0.05$.

\section{Results}

In this study, 61 glaucoma patients who underwent TET were analyzed retrospectively. In group 1, 34 glaucoma patients received subconjunctival 5-FU only. In group 2, 27 glaucoma patients received subconjunctival bevacizumab as an adjunct to subconjunctival 5-FU. All patients received topical MMC intraoperatively. Demographics and patient data, summarized in Table 1, revealed no statistically significant differences between the two groups preoperatively.

Group 1 had $6.4 \pm 3.3,0-15$ (mean $\pm \mathrm{SD}$, range) $5-\mathrm{FU}$ injections and group 2 had $4.0 \pm 2.8,0-12$ (mean $\pm \mathrm{SD}$, range) 5-FU injections. The added injection of bevacizumab significantly reduced the mean number of 5-FU injections by $2.4 \pm 3.08(P \leq 0.005)$. Patients in group 2 received 
Table I Baseline patient characteristics $(\mathrm{N}=6 \mathrm{I})$

\begin{tabular}{ll}
\hline Age, years (mean \pm SD) & $67 \pm 9.7$ \\
Range, years & $35-86$ \\
Sex, male/female, N & $25 / 36$ \\
Follow-up, months (mean \pm SD) & $25 \pm 19.1$ \\
Range, months & $1-8 \mathrm{I}$ \\
Eye, OD/OS, N & $26 / 35$ \\
Previous surgeries, N (mean \pm SD) & $1 \pm 1.0$ \\
Range & $0-4$ \\
Previous argon laser trabeculoplasty, N (mean \pm SD) & $0.5 \pm 0.6$ \\
Range & $0-2$ \\
Glaucoma diagnosis, N & \\
POWG & 33 \\
PEX & 14 \\
PDG & 4 \\
NTG & 5 \\
OHT & 2 \\
PACG & 2 \\
Applied intraoperative MMC, N & \\
0.0I\% & 2 \\
0.02\% & 52 \\
0.05\% & 7 \\
Second operations, N (mean $\pm S D)$ & $1 \pm 1$ \\
Range & $0-4$ \\
Laser suture lysis, N (mean $\pm S D)$ & $1 \pm 1.4$ \\
Range & $0-7$ \\
\hline
\end{tabular}

Abbreviations: MMC, mitomycin C; N, number; NTG, normal tension glaucoma; $\mathrm{OD}$, right eye; $\mathrm{OHT}$, ocular hypertension; OS, left eye; PACG, primary angle closure glaucoma; PDG, pigment dispersion glaucoma; PEX, pseudoexfoliation glaucoma; POWG, primary open angle glaucoma; SD, standard deviation.

one bevacizumab injection. Topical steroids were applied as standard to each patient's eye in both groups (6-8 times a day). Patients with intolerance to preservatives received Dexasine ${ }^{\circledR}$ SE (Alcon Pharma GmBH, Freiburg im Breisgau, Germany). All other patients received $10 \mathrm{mg} / \mathrm{mL}$ Inflanefran ${ }^{\circledR}$ forte (Allergan Pharmaceuticals, Irvine, CA, USA).

In group 1, preoperative IOP was lowered from $24 \pm 6.0 \mathrm{mmHg}, 15-37 \mathrm{mmHg}$ (mean $\pm \mathrm{SD}$, range) to $12 \pm 2.0 \mathrm{mmHg}, 8-17 \mathrm{mmHg}$ (mean $\pm \mathrm{SD}$, range) at last follow-up (Table 2). In group 2, preoperative IOP was lowered from $24 \pm 6.0 \mathrm{mmHg}, 14-37 \mathrm{mmHg}$ (mean $\pm \mathrm{SD}$, range) to $11 \pm 3.0 \mathrm{mmHg}, 6-16 \mathrm{mmHg}$ (mean $\pm \mathrm{SD}$, range) at last follow-up (Table 2). For both groups, preoperative IOP was lowered from $24 \pm 6.0,14-37$ (mean \pm SD, range) to $12 \pm 3.0,6-17$ (mean $\pm \mathrm{SD}$, range) at last follow-up (Table 2). Success rates are summarized in Table 2 and Figure 1. Pre- to postoperative changes in IOP are illustrated in Table 2. There was no significantly lower IOP in group 2 when compared to group 1 at 12 months and at last follow-up.

The BCVA in group 1 remained stable at mean decimal vision of $0.8(\mathrm{~N}=34)$ preoperatively to after approximately
12 months $(\mathrm{N}=12)$, and at last follow-up $(\mathrm{N}=24)$. In group 2, BCVA changed from mean decimal vision of 0.62 $(\mathrm{N}=27)$ preoperatively to $0.56(\mathrm{~N}=17)$ after 12 months, and to $0.35(\mathrm{~N}=17)$ at last follow-up. No significant difference in BCVA $(P=0.852)$ between preoperative to last follow-up could be found between the two groups. Data is illustrated in Table 2.

The visual field screening in group 1 changed from a mean deviance (MD) of $7.5 \pm 7.0,-1.1$ to 22.1 (mean $\pm \mathrm{SD}$, range; $\mathrm{N}=31)$ preoperatively to $8.2 \pm 6.3,1.3-21.7$ (mean $\pm \mathrm{SD}$, range; $\mathrm{N}=22$ ) at last follow-up. Visual field screening in group 2 changed from a MD of $10.5 \pm 7.6$, 0-23.9 (mean $\pm \mathrm{SD}$, range; $\mathrm{N}=25$ ) preoperatively to $12.0 \pm 7.7,0.9-24.0$ (mean $\pm \mathrm{SD}$, range; $\mathrm{N}=15$ ) at last follow-up. No significant difference in visual field screening $(P=0.610)$ between preoperative to last follow-up could be found between the two groups. Data are illustrated in Table 2.

The Wilcoxon test showed a significant reduction in vascularization and cork screw vessels in both groups ( $P<0.001,7$ days to last follow-up). Vascularizations in group 1 were significantly higher from day 1 until 3 months postoperatively in comparison to last follow-up, and from day 1 until 1 month in comparison to last follow-up in group 2. Cork screw vessels in group 1 were significantly higher from day 7 until 1 month postoperatively in comparison to last follow-up, and from day 1 until 1 month in group 2 in comparison to last follow-up. The lack of significance between the postoperative results when compared to the last follow-up may be due to the small sample size of evaluated blebs postoperatively. There was no difference between the two groups at last follow-up. The Wilcoxon test showed no significant difference in encapsulation $(P=0.391)$ and microcysts $(P=0.745)$ between 7 days and last follow-up. Results are shown in Figure 2.

Patients in both groups received $0.6 \pm 1.0,1-4$ (mean $\pm \mathrm{SD}$, range) surgical interventions after TET. In eyes where re-interventions occurred significantly more often, when more injections of 5-FU were applied $(P=0.008)$ in both groups. The types of re-interventions are summarized in Table 3. Preoperatively, group 1 received $2.1 \pm 1.0$, 0-4 (mean $\pm \mathrm{SD}$, range) and group 2 received $2.5 \pm 0.9$, 1-4 (mean $\pm \mathrm{SD}$, range) antiglaucomatous medications. Postoperatively, group 1 received $0.1 \pm 0.4,0-2$ (mean \pm SD, range) and group 2 received $0.2 \pm 0.5,0-2$ (mean $\pm \mathrm{SD}$, range) antiglaucomatous medications respectively. There was no significant difference between the groups pre- $(P=0.121)$ and postoperatively $(P=0.434)$. 
Table 2 Preoperative and postoperative comparisons

\begin{tabular}{|c|c|c|c|c|}
\hline & 5-FU group & $\begin{array}{l}\text { 5-FU and bevacizumab } \\
\text { group }\end{array}$ & Total & $\begin{array}{l}P \text {-value between } \\
\text { groups }\end{array}$ \\
\hline \multicolumn{5}{|c|}{ Antiglaucomatous medications, $\mathrm{N}$ (mean $\pm \mathrm{SD})$} \\
\hline Preoperative & $2.1 \pm 1.0$ & $2.5 \pm 0.9$ & $2.3 \pm 1$ & 0.121 \\
\hline Range & $0-4$ & $1-4$ & $0-4$ & \\
\hline Postoperative & $0.1 \pm 0.4$ & $0.2 \pm 0.5$ & $0.2 \pm 0.5$ & 0.434 \\
\hline Range & $0-2$ & $0-2$ & $0-2$ & \\
\hline \multicolumn{5}{|c|}{ Preoperative lens status, $\mathrm{N}$} \\
\hline Phakic & 31 & 21 & 52 & 0.167 \\
\hline Pseudophakic & 3 & 6 & 9 & \\
\hline \multicolumn{5}{|c|}{ Lens status 12 months/last follow-up, $\mathrm{N}$} \\
\hline Phakic & 26 & 16 & 42 & 0.174 \\
\hline Pseudophakic & 8 & 11 & 19 & \\
\hline \multicolumn{5}{|c|}{ IOP, mmHg (mean $\pm S D$, range) } \\
\hline Preoperative & $24 \pm 6(15-37)$ & $24 \pm 6(14-37)$ & $24 \pm 6(14-37)$ & 0.989 \\
\hline Postoperative & $12 \pm 2(8-17)$ & $11 \pm 3(6-16)$ & $12 \pm 3(6-17)$ & 0.380 \\
\hline \multicolumn{5}{|l|}{ BCVA, decimal } \\
\hline Preoperative & 0.8 & 0.62 & & 0.213 \\
\hline Postoperative & 0.8 & 0.35 & & 0.162 \\
\hline \multicolumn{5}{|c|}{ Visual field (MD $\pm S D$, range) } \\
\hline Preoperative & $7.5 \pm 7(-1.1$ to 22.1$)$ & $10.5 \pm 7.6(0-23.9)$ & $9 \pm 7.3(-1.1$ to 23.9$)$ & 0.126 \\
\hline Postoperative & $8.2 \pm 6.3(1.3-21.7)$ & $12.0 \pm 7.7(0.9-24.0)$ & $10 \pm 7.1(0.9-24)$ & 0.106 \\
\hline Complete success ${ }^{\mathrm{a}}$ & $78.79 \%(\mathrm{~N}=26)$ & $85.19 \%(N=23)$ & $81.67 \%(\mathrm{~N}=49)$ & 0.739 \\
\hline Complete success $^{\mathrm{b}}$ & $84.85 \%(\mathrm{~N}=28)$ & $81.48 \%(\mathrm{~N}=22)$ & $83.33 \%(\mathrm{~N}=50)$ & 0.742 \\
\hline Qualified success ${ }^{c}$ & $85.29 \%(\mathrm{~N}=29)$ & $100.0 \%(\mathrm{~N}=27)$ & $91.80 \%(\mathrm{~N}=56)$ & 0.060 \\
\hline Qualified success $^{d}$ & $100.0 \%(\mathrm{~N}=34)$ & $100.0 \%(\mathrm{~N}=27)$ & $100.0 \%(\mathrm{~N}=61)$ & 1 \\
\hline
\end{tabular}

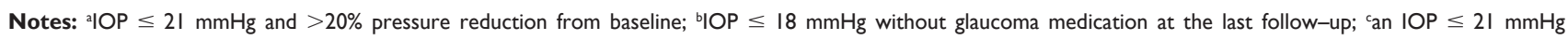
and $>20 \%$ pressure reduction from baseline; and "IOP $\leq 18 \mathrm{mmHg}$ with and without glaucoma medication at the last follow-up. "Postoperative" indicates the time point at last follow-up. The comparison here is between preoperative and last follow up (postoperative time point: last follow up).

Abbreviations: 5-FU, 5-fluororacil; BCVA, best corrected visual acuity; IOP, intraocular pressure; MD, mean deviance; SD, standard deviation.

\section{Discussion}

VEGF has been described to have multiple effects on wound healing, such as angiogenesis and enhancement of scar formation. ${ }^{7,8}$ It has also been shown to be elevated in glaucoma patients. ${ }^{9-11}$ Therefore, bevacizumab, as a VEGF antibody, may have the potential to reduce elevated VEGF levels, angiogenesis, and scar formation. ${ }^{12}$ Current case reports and studies in animals have shown a tendency for reduced bleb failure and postoperative scarring after subconjunctival injections of bevacizumab as an adjunct to 5-FU or when used alone. ${ }^{13-17}$ Memarzadeh et al reported a significant reduction in postoperative scarring on a microscopic level and prolonged bleb survival when comparing bevacizumab to 5-FU and a balanced salt solution, respectively, in rabbits, even though a statistically significant difference in IOP reduction could not be found. ${ }^{17}$ Esson et al reported an increase in VEGF in the bleb tissue of rats and $\mathrm{Li}$ et al reported an increase in VEGF in the aqueous humor of rabbits..$^{20,21}$ The application of bevacizumab subconjunctivally and into the anterior chamber intraoperatively did not lead to a better IOP lowering, but to a larger bleb area after the Moorfields bleb classification, thus implementing a reduction in scar formation..$^{21}$ These animal studies may implicate a possible benefit in applying postoperative bevacizumab to suppress further upregulation of VEGF production. How et al reported the highest bleb survival rate in a rabbit model when subconjunctival bevacizumab was combined with 5-FU (100\%). ${ }^{16}$ Interestingly, the application of bevacizumab alone still led to a higher survival rate (50\%) than 5-FU (25\%) alone. ${ }^{16}$ The control group showed no bleb survival. These findings support the idea of a potential benefit of postoperative scar inhibition by bevacizumab, and are consistent with the results of this study, by reducing the postoperative amount of 5-FU when bevacizumab is applied in addition to 5-FU. The findings of the animal studies are also consistent with published in vitro studies. O'Neill et al detected a reduction in fibroblast proliferation and collagen gel contraction ability after bevacizumab application. ${ }^{23}$ $\mathrm{Li}$ et al reported a significant increase in human and rabbit tenon fibroblast proliferation in tissue culture when VEGF was added. ${ }^{21}$ To date, only a few case reports and pilot studies on glaucoma patients have looked at the effect of VEGF inhibitors to prevent postoperative scarring. ${ }^{13,14}$ In a pilot 


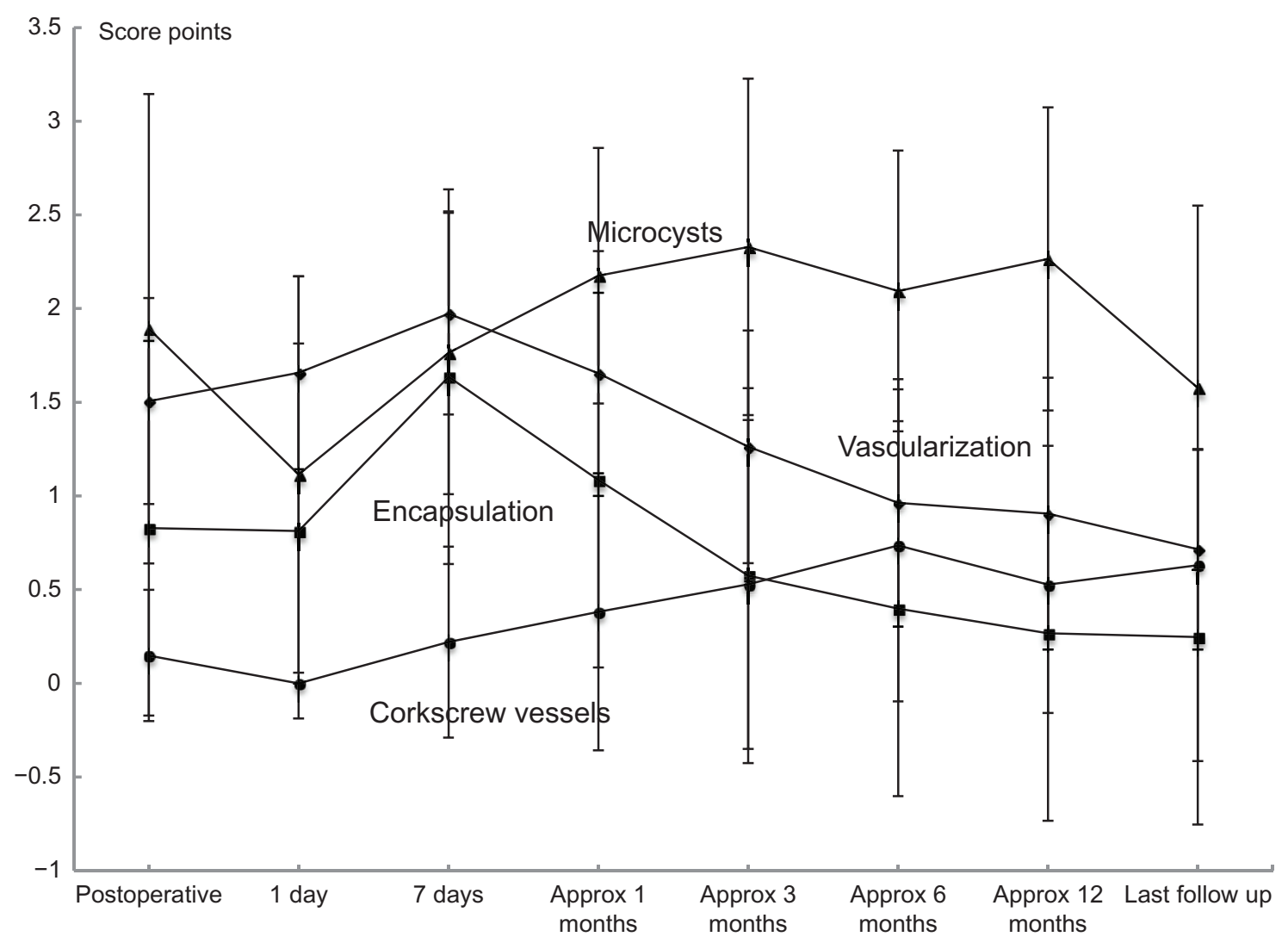

Figure I Intraocular pressure values preoperative to 12 months/last follow-up.

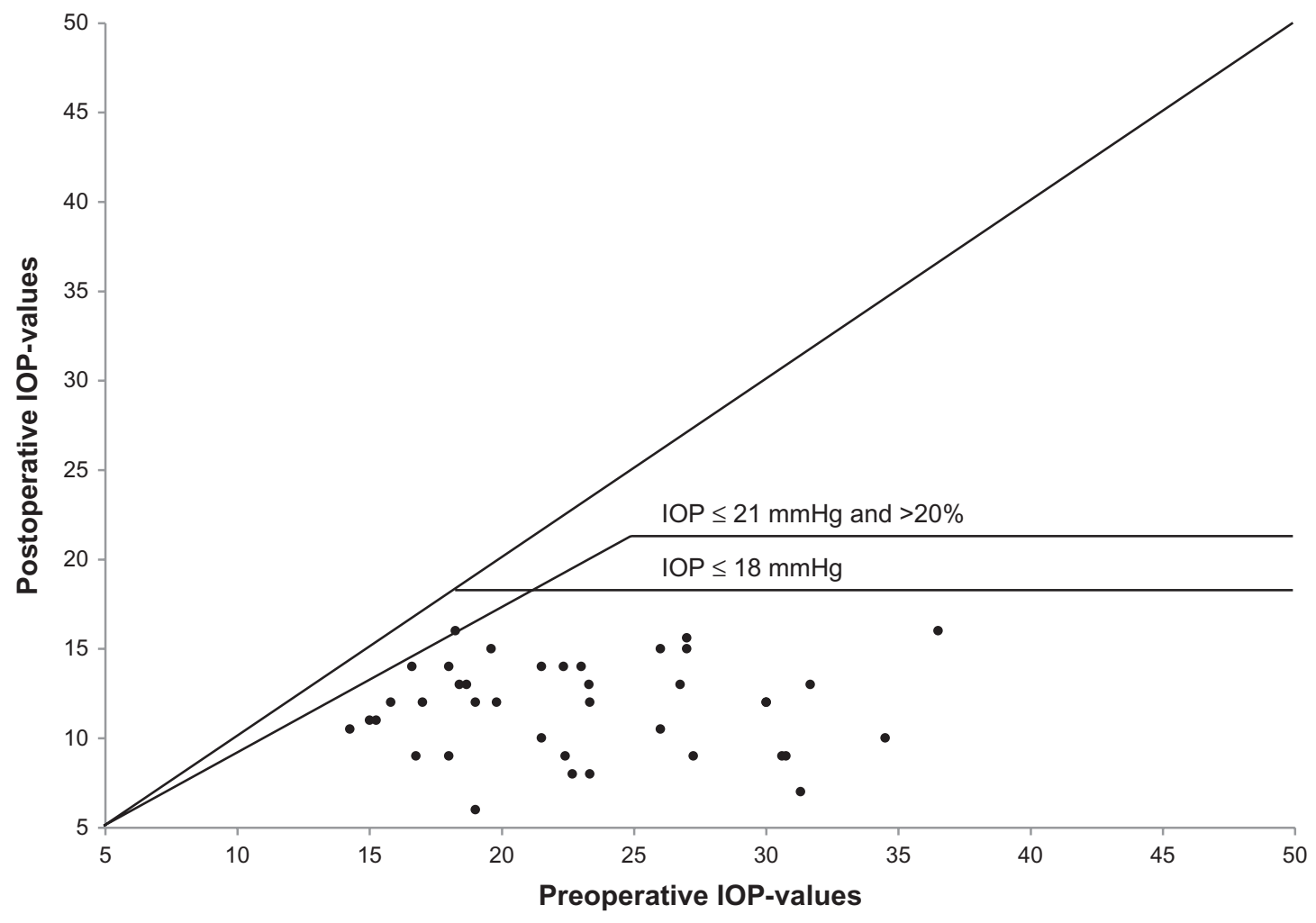

Figure 2 Mean score of filtering bleb morphology over time. Abbreviation: IOP, intraocular pressure. 
Table 3 Postoperative complications and interventions

\begin{tabular}{|c|c|c|c|c|}
\hline & 5-FU group & $\begin{array}{l}\text { 5-FU and bevacizumab } \\
\text { group }\end{array}$ & Total & $\begin{array}{l}P \text {-value between } \\
\text { the groups }\end{array}$ \\
\hline \multicolumn{5}{|l|}{ Bleb failure } \\
\hline Bleb needling & 14 & 4 & 20 & 0.046 \\
\hline Re-TET & 3 & 0 & 3 & 0.248 \\
\hline YAG-goniopuncture & 0 & 2 & 2 & 0.192 \\
\hline Cyclophotocoagulation & 1 & 0 & I & I \\
\hline \multicolumn{5}{|l|}{ Hypotony } \\
\hline Resutures of the scleral flap & 7 & I & 8 & 0.066 \\
\hline Injection of Healon-GV ${ }^{\circledR}$ & 1 & 0 & I & I \\
\hline \multicolumn{5}{|l|}{ (Abbott Laboratories Inc, } \\
\hline \multicolumn{5}{|l|}{ Abbot Park, IL, USA) } \\
\hline \multicolumn{5}{|l|}{ Others } \\
\hline Irrigation of the AC & 1 & 0 & I & 1 \\
\hline Iris repositioning & 2 & 2 & 4 & I \\
\hline
\end{tabular}

Abbreviations: AC, anterior chamber; Re-TET, re-trabeculectomy; YAG, yttrium aluminum garnet; 5-FU, 5-fluororacil.

study, Grewal et al injected bevacizumab subconjunctivally at the end of trabeculectomy. ${ }^{14}$ Twelve eyes were observed and after a mean follow-up period of 182 days, a successful trabeculectomy with respect to IOP control was observed in 11 eyes (92\%), with an average IOP reduction of 52\%. ${ }^{14}$ An open label pilot study by Kahook et al injected ranibizumab in addition to MMC and compared this with MMC alone. ${ }^{13}$ Statistically significant differences in peripheral bleb area, peripheral bleb vascularity, nonbleb-related peripheral conjunctiva vascularity, and more diffuse blebs with a lower degree of vascularity were found in the group with intravitreal ranibizumab.

Postoperative scarring remains the most frequent cause for bleb failure and thus a rise in IOP after filtering surgery ${ }^{3}$ makes it necessary to inhibit scar formation. Antimetabolites, such as 5-FU and MMC, are the current standard to prevent blebs from postoperative scar formation. ${ }^{4}$ The described complications of antimetabolites, such as bleb leakage, hypotony, corneal scarring, and endophthalmitis ${ }^{5,6}$ support the potential benefit of bevacizumab. In this study, less postoperative complications, such as hypotony and re-interventions, were found in group 2, even though these differences were not statistically significant. In both groups of this study, the complication rate increased with the number of 5-FU injections applied. Bevacizumab decreases the need for 5-FU and thus reduces the postoperative complication rate. The increased levels of VEGF in glaucoma patients and TET operated eyes, as well as the inhibition of scar formation and the positive effect on bleb function, further support the potential benefit of bevacizumab as a postoperative inhibitor of scar formation. ${ }^{13,14,16,17,21,22}$ Even though a statistically significant difference in IOP and bleb morphology could not be found in this study, the additional injection of bevacizumab reduced the number of 5-FU injections.

It is uncertain whether topical, subconjunctival, or intravitreal administration is the optimal route for administration of bevacizumab. Most studies focus on bevacizumab application for retinal use. A study by Nomoto et al in rabbit eyes has shown that bevacizumab applied subconjunctivally had a longer half-life than intravitreal application. ${ }^{24}$ This may indicate that subconjunctival injection is the optimal route for administration. Further studies are needed to determine the optimal route for application of bevacizumab for the inhibition of scarring on the bleb area, as well as the optimal time of application and dosage. The dosage of bevacizumab in animal studies ranged from $1.25 \mathrm{mg}$ bevacizumab applied 1-7 times subconjunctivally, to $2.5 \mathrm{mg}$ applied subconjunctivally, and $1.25 \mathrm{mg}$ applied intravitreal. ${ }^{12,16,17}$ In patients, $1.5 \mathrm{mg}$ of bevacizumab and $0.5 \mathrm{mg}$ of ranibizumab were injected in comparison to $3.5 \mathrm{mg}$ of bevacizumab in our study. ${ }^{13,14}$ These differences in dosage, time of application, and route of application make comparisons of these studies difficult. Nevertheless, in vitro studies, animal studies, and studies in glaucoma patients all support the potential benefit of bevacizumab as an inhibitor of postoperative scar formation after TET.

This study has shown a reduction in the number of 5-FU applications when bevacizumab was applied as an adjunct, and is followed by similar success rates. More postoperative complications occurred in patients with a higher number of 5-FU applications. Now, further prospective, randomized studies are needed to investigate the effect of subconjunctival bevacizumab alone or as an adjunct to 5-FU versus 5-FU respectively in postoperative care after TET and to determine an optimal route of application, time of application, and dosage. 


\section{Disclosure}

The authors declare no conflict of interest in this work.

\section{References}

1. O'Brien C, Schwartz B, Takamoto T, Wu DC. Intraocular pressure and the rate of visual field loss in chronic open-angle glaucoma. $A m J$ Ophthalmol. 1991;111(4):491-500.

2. Cairns JE. Trabeculectomy. Preliminary report of a new method. Am J Ophthalmol. 1968;66(4):673-679.

3. Reddick R, Merritt JC, Ross G, Avery A, Peiffer RL. Myofibroblasts in filtration operations. Ann Ophthalmol. 1985;17(3):200-203.

4. Mostafaei A. Augmenting trabeculectomy in glaucoma with subconjunctival mitomycin $\mathrm{C}$ versus subconjunctival 5-fluorouracil: a randomized clinical trial. Clin Ophthalmol. 2011;5:491-494.

5. Greenfield DS, Suñer IJ, Miller MP, Kangas TA, Palmberg PF, Flynn HW Jr. Endophthalmitis after filtering surgery with mitomycin. Arch Ophthalmol. 1996;114(8):943-949.

6. Seah SK, Prata JA Jr, Minckler DS, Baerveldt G, Lee PP, Heuer DK. Hypotony following trabeculectomy. J Glaucoma. 1995;4(2): 73-79.

7. Bao P, Kodra A, Tomic-Canic M, Golinko MS, Ehrlich HP, Brem H. The role of vascular endothelial growth factor in wound healing. J Surg Res. 2009;153(2):347-358.

8. Nissen NN, Polverini PJ, Koch AE, Volin MV, Gamelli RL, DiPietro LA. Vascular endothelial growth factor mediates angiogenic activity during the proliferative phase of wound healing. Am J Pathol. 1998;152(6): 1445-1452.

9. Lopilly Park HY, Kim JH, Ahn MD, Park CK. Level of vascular endothelial growth factor in tenon tissue and results of glaucoma surgery. Arch Ophthalmol. 2012;130(6):685-689.

10. Tripathi RC, Li J, Tripathi BJ, Chalam KV, Adamis AP. Increased level of vascular endothelial growth factor in aqueous humor of patients with neovascular glaucoma. Ophthalmology. 1998;105(2):232-237.

11. Hu DN, Ritch R, Liebmann J, Liu Y, Cheng B, Hu MS. Vascular endothelial growth factor is increased in aqueous humor of glaucomatous eyes. J Glaucoma. 2002;11(5):406-410.

12. Miyake T, Sawada O, Kakinoki M, et al. Pharmacokinetics of bevacizumab and its effect on vascular endothelial growth factor after intravitreal injection of bevacizumab in macaque eyes. Invest Ophthalmol Vis Sci. 2010;51(3):1606-1608.
13. Kahook MY, Schuman JS, Noecker RJ. Intravitreal bevacizumab in a patient with neovascular glaucoma. Ophthalmic Surg Lasers Imaging. 2006;37(2):144-146.

14. Grewal DS, Jain R, Kumar H, Grewal SP. Evaluation of subconjunctival bevacizumab as an adjunct to trabeculectomy a pilot study. Ophthalmology. 2008;115(12):2141. e2-2145. e2.

15. Nilforushan N, Yadgari M, Kish SK, Nassiri N. Subconjunctival bevacizumab versus mitomycin $\mathrm{C}$ adjunctive to trabeculectomy. Am J Ophthalmol. 2012;153(2):352. e1-357. e1.

16. How A, Chua JL, Charlton A, et al. Combined treatment with bevacizumab and 5-fluorouracil attenuates the postoperative scarring response after experimental glaucoma filtration surgery. Invest Ophthalmol Vis Sci. 2010;51(2):928-932.

17. Memarzadeh F, Varma R, Lin LT, et al. Postoperative use of bevacizumab as an antifibrotic agent in glaucoma filtration surgery in the rabbit. Invest Ophthalmol Vis Sci. 2009;50(7):3233-3237.

18. Klink T, Schrey S, Elsesser U, Klink J, Schlunck G, Grehn F. Interobserver variability of the Wurzburg bleb classification score. Ophthalmologica. 2008;222(6):408-413.

19. Klink T, Kann G, Ellinger P, Klink J, Grehn F, Guthoff R. The prognostic value of the Wuerzburg bleb classification score for the outcome of trabeculectomy. Ophthalmologica. 2011;225(1):55-60.

20. Esson DW, Popp MP, Liu L, Schultz GS, Sherwood MB. Microarray analysis of the failure of filtering blebs in a rat model of glaucoma filtering surgery. Invest Ophthalmol Vis Sci. 2004;45(12):4450-4462.

21. Li Z, Van Bergen T, Van de Veire S, et al. Inhibition of vascular endothelial growth factor reduces scar formation after glaucoma filtration surgery. Invest Ophthalmol Vis Sci. 2009;50(11):5217-5225.

22. Mathew R, Barton K. Anti-vascular endothelial growth factor therapy in glaucoma filtration surgery. Am J Ophthalmol. 2011;152(1): 10. e2-15. e2.

23. O'Neill EC, Qin Q, Van Bergen NJ, et al. Antifibrotic activity of bevacizumab on human Tenon's fibroblasts in vitro. Invest Ophthalmol Vis Sci. 2010;51(12):6524-6532.

24. Nomoto H, Shiraga F, Kuno N, et al. Pharmacokinetics of bevacizumab after topical, subconjunctival, and intravitreal administration in rabbits. Invest Ophthalmol Vis Sci. 2009;50(10):4807-4813.
Clinical Ophthalmology

\section{Publish your work in this journal}

Clinical Ophthalmology is an international, peer-reviewed journal covering all subspecialties within ophthalmology. Key topics include: Optometry; Visual science; Pharmacology and drug therapy in eye diseases; Basic Sciences; Primary and Secondary eye care; Patien Safety and Quality of Care Improvements. This journal is indexed on Submit your manuscript here: http://www.dovepress.com/clinical-ophthalmology-journal

\section{Dovepress}

PubMed Central and CAS, and is the official journal of The Society of Clinical Ophthalmology (SCO). The manuscript management system is completely online and includes a very quick and fair peer-review system, which is all easy to use. Visit http://www.dovepress.com/ testimonials.php to read real quotes from published authors. 